\title{
AUDIT SYSTEM FOR BLOOD PRODUCT USAGE IN SANGLAH GENERAL HOSPITAL DENPASAR BALI
}

\author{
Ni Kadek Mulyantari ${ }^{1}$, Teguh Triyono ${ }^{2}$, Usi Sukorini ${ }^{2}$ \\ ${ }^{1}$ Department of Clinical Pathology, Faculty of Medicine, Udayana University/Sanglah General Hospital Bali, Indonesia. E-mail: \\ melyan79@yahoo.co.id \\ ²Department of Clinical Pathology, Faculty of Medicine, Gadjah Mada University/Dr.Sardjito Yogyakarta, Indonesia. E-mail: \\ pakteguhtri@yahoo.com
}

\section{ABSTRACT}

Blood transfusion is one of the essential therapy components. One indicator of the blood services quality in Sanglah General Hospital Denpasar Bali Indonesia is achieving the target of unused blood order $\leq 10 \%$ per month. These targets have not been achieved. The number of unused blood orders reached 6,719 bags per year (600 bags per month or $21.5 \%$ ). Unused blood orders were mostly from Department of Internal Medicine (40.9\%), followed by Department of Surgical (35.6\%), Department of Obstetrics and Gynecology (15.5\%), and Department of Pediatrics (8\%). The condition can cause several problems such as the disorder of blood supply, the inefficiency of pre-transfusion testing, and decreased quality of blood product. Base on the condition, it is necessary to research audit system for usage of blood product in the Sanglah Hospital. The study aimed to analyze the influence of audit system to reduce unused blood order and to decrease the number of Crossmatch per Transfusion ratio (C/T ratio). Design of study was a pre and posttest intervention study. The population in this study were all forming of blood requests in the Sanglah Hospital. The sample was a blood request form the Department of Internal Medicine of the last two months. Intervention in this study was the development and dissemination of guidelines for the use of blood products, followed by concurrent audit and prospective audit of the sample. The study showed there were decline of the unused blood orders and $\mathrm{C} / \mathrm{T}$ ratio before and after implementation of the audit system for usage of blood products. Reduction of unused blood order in the Sanglah Hospital was 5.4\%, and in the Department of Internal Medicine was $5.2 \%$. The causes of unused blood orders were patient died, overestimation of blood order, transfusion delays because of waiting for the schedule of hemodialysis, the patient had fever, blood product, and the occurrence of administration errors. Reduction of the C/T ratio in the Sanglah Hospital was 0.094 and in the Department of Internal Medicine is 0,072. An audit system for usage of blood products can reduce unused blood orders and decrease C/T ratio.

Key words: Audit system, blood products, the $\mathrm{C} / \mathrm{T}$ ratio, unused blood orders

\section{INTRODUCTION}

Blood transfusion is one of the crucial components of therapy in patient management. Blood transfusions have to adhere to the principle that the benefits accruing to the patient are higher than the risk to be borne. Transfusion will be beneficial if it is administered with the right indication, the right blood type, right dose, right time, right administration, and always be aware of the side effects. ${ }^{1}$

Based on the data in 2012, the use of blood at the Sanglah General Hospital was at an average of 2,155 bags per month. Sixty-six percent of the demand for blood came from the Internal Medicine Department, $12 \%$ from the Surgical Department, 10\% from the Pediatrics Department, 8\% from the Obstetrics and Gynecology Department and 4\% from other

\section{Departments. $^{2}$}

One of the indicators used to determine the rationality demand for blood is a $C / T$ ratio (crossmatch/transfusion ratio). Based on the calculation of the $\mathrm{C} / \mathrm{T}$ ratio, the monthly average reaches. ${ }^{2,3}$ The ideal of $\mathrm{C} / \mathrm{T}$ ratio is one. ${ }^{3}$ Based on this figure, Sanglah Hospital is currently not included in the ideal category. One of the indicators of quality of service set by the Sanglah Hospital to be accredited internationally according to the standards of Joint Commission International (JCI) is the achievement of targets that the unused blood order must be $\leq 10 \%$ permonth. ${ }^{2}$

However, the facts that occurred in 2012 show the state that did not comply with the target. Total unused blood order reached 6,719 bags per year. If the numbers were distributed to each month, then every month there were 600 bags or $21.5 \%$ of unused 
blood order. The incidence of unused blood order mostly occurred in the Department of Internal Medicine at $40.9 \%$. The second place was at the Surgical Department, namely 35.6\%, Obstetrics and Gynecology Department at $15.5 \%$ and the Pediatrics Department at $8 \%{ }^{2}$

The main problem is the disruption of the blood supply, especially when the blood supply decreases. Patients who need the blood can be delayed because of blood stocks are already prepared for other patients who eventually canceled using the blood. Another issue that arises is the inefficiency of the components of the pretransfusion examination and the declining quality of the blood. The decline in the quality of blood is due to the prolonged period of storage of blood products. ${ }^{2,4}$

Given the many problems that arise due to the high amount of unused blood order, then it was necessary to research audit systems of the use of blood products in the Sanglah Hospital Denpasar.

\section{METHODS}

Design of the study was an intervention study of pre and posttest. The population covers the entire demand of blood products at Sanglah General Hospital Denpasar, and then the research sample was all the demand for blood for two months at the Department of Internal Medicine of Sanglah Hospital Denpasar. The research was conducted in the Blood Bank and the entire patient-care areas of the Department of Internal Medicine at Sanglah General Hospital Denpasar, which conducted blood transfusions. The research was conducted from January to August 2013. Ethical clearance in this study was obtained from the Commission for Research Ethics at the Faculty of Medicine Udayana University/Sanglah General Hospital Bali with 696/UN.14.2/Litbang/2013.

Variables of this study include the audit system of the use of blood products, the incidence of unused blood order and the $\mathrm{C} / \mathrm{T}$ ratio. The audit systems of the use of blood products was a method used to evaluate whether the use of blood was folowing the guidelines, and the right criteria, and to improve the quality of the practice of using the blood. The blood products were all blood products removed from the blood bank of Sanglah Hospital, which was used in transfusion practices throughout the treatment room of the Department of Internal Medicine Sanglah Hospital Denpasar. The blood products included Packed Red Cells (PRC) and Thrombocyte Concentrate (TC). Unused blood order is the percentage of blood that had been prepared but had failed to be used per the total of the entire blood demand multiplied by one hundred percent. the $\mathrm{C} / \mathrm{T}$ Ratio was the ratio of the number of crossmatch inspection divided by the number of transfusions performed during the same period.

Analysis of the results was carried out by analyzing the average decline in the incidence of Unused Blood Order and the C/T Ratio before and after the application of the audit systems of the use of blood products.

\section{RESULTS AND DISCUSSION}

In the first month of the implementation audit systems (16 June-15 July 2013) There were 236 request forms, and in the second month of the application of the audit system (July 16 -15 August 2013), there were 274 blood request forms from the Department of Internal Medicine. When it was compared with the results of the request review for blood in 2012, the completeness of the writing of the request form tended to be better although still to be improved. Most of the data had not included a history of previous blood transfusion. From a total of 510 blood, $214(41.9 \%)$ of the request came from the hematology subdivision, 182 (35.7\%) from the nephrology subdivision, 51 (10\%) from the gastro-hepatology subdivision, 16 (3.1\%) from the subdivision of trophic disease, 15 (2.3\%) from the subdivision of pulmonary, 11 (2.2\%) from the subdivision of Immunology, 6 (1.2\%) from the endocrine subdivision and a total of $18(3.5 \%)$ was not known.

A total of $459(90 \%)$ requests only asked for the PRC component, 26 (5.09\%) only for TC component and the remaining 25 requests (4.91\%) asked for the PRC and TC. The indication of transfusion was based on the levels of hemoglobin. A total of 263 (54.4\%) patients had hemoglobin levels $<7 \mathrm{~g} / \mathrm{dL}$, 87 (17.9\%) with hemoglobin levels 7 to $7.9 \mathrm{~g} / \mathrm{dL}, 76$ (15.8\%) were from 8 to $8.9 \mathrm{~g} / \mathrm{dL}, 19$ (3.9\%) hemoglobin levels from 9 to $9.9 \%$ and the remaining 39 patient hemoglobin levels (8.06\%) were not specified in the blood requests. The 51 requests of TC, 29 (56.86\%) have included the platelet counts, and as many as 22 (43.14\%) have not included the platelet counts. Among the 29 requests for TC, 16 (31.37\%) with the platelet counts of $\leq 10,000 / \mu \mathrm{L}, 10$ (19.6\%) with the platelet counts of $10,000-20,000 / \mu \mathrm{L}, 2(3.92 \%)$ with the platelet counts of $20,000-40,000 / \mu \mathrm{L}, 1$ (1.96\%) with a platelet count of $>40,000 / \mu \mathrm{L}$. On platelets of $>$ $40000 / \mu \mathrm{L}$ or more precisely $45,000 / \mu \mathrm{L}$, platelet 
transfusion was done to meet the requirements of operations that require the platelet count of at least $750,000 / \mu \mathrm{L}$.

It was still found incomplete form filling of the blood requests, especially about the history of previous blood transfusion. It could be due to the recording system in the patient medical record was still done manually. The doctor would find it difficult to retrace it if there was quite far distance between the previous periods of transfusion. Transfusion history discovery difficulty was also common in patients who had the previous transfusion outside Sanglah General Hospital. Patients often did not carry a note or record of their therapy taken outside the Sanglah General Hospital, and transfusion history search through anamnesis of patients was also quite difficult. Patients often forgot or could not provide the information. Transfusion history search in the Blood Bank also often experienced problems because the recording was still done manually. It takes quite a long time to find the data of the previous transfusion.

Filling the request form completely and correctly is essential knowledge and skills in the practice of transfusion. ${ }^{5}$ Proof of blood requests also must be documented in the patient medical record. The accuracy of the recording of blood requests, including documentation of the reasons and type of blood component transfusion is very important for tracking cases in the event of serious side effects of transfusion, or in case of medico-legal cases. ${ }^{6}$

The following is a table which explains the incident of unused blood order before and after the implementation of the audit systems at the Sanglah Public General Hospital.

In Table 1, the average incidence of unused blood

Table 1. The unused blood order incidents before and after the blood audit system was applied in the Sanglah General Hospital

\begin{tabular}{lccc}
\hline Month & $\boldsymbol{\Sigma N}$ Numerator* $^{*}$ & $\boldsymbol{\Sigma}^{\text {Denumerator** }}$ & Result (\%) \\
\hline January & 614 & 2613 & $23 \%$ \\
February & 586 & 2023 & $29 \%$ \\
March & 654 & 2590 & $25 \%$ \\
April & 593 & 2553 & $23 \%$ \\
Mei & 631 & 3093 & $20.5 \%$ \\
Juni & 533 & 2773 & $19.2 \%$ \\
July & 538 & 2856 & $24.1 \%$ \\
Mean before implementation of the & & & $18.51 \%$ \\
audit system & & 2701 & $18.90 \%$ \\
The first month of audit & 500 & 2502 & $18.71 \%$ \\
The second month of audit & 473 & & \\
Mean after implementation of the & & & \\
audit system & & & \\
\hline
\end{tabular}

* Numerator: Number of unused blood ordered in a month (bag)

**Denumerator: Number of all blood ordered within a similar month (bag)

Table 2. Incidents of unused blood order before and after the blood audit system applied in the Internal Medicine Department

\begin{tabular}{lccc}
\hline Month & $\boldsymbol{\Sigma}$ Numerator* & $\boldsymbol{\Sigma}^{*}$ Denumerator** & Result (\%) \\
\hline January & 304 & 1824 & $16.67 \%$ \\
February & 322 & 1777 & $18.12 \%$ \\
March & 326 & 1706 & $19.11 \%$ \\
April & 223 & 1263 & $17.65 \%$ \\
Mei & 246 & 1318 & $18.66 \%$ \\
Juni & 233 & 1769 & $13.17 \%$ \\
July & 216 & 1597 & $13.52 \%$ \\
The first month of audit & 164 & 1295 & $12.68 \%$ \\
The second month of audit & 175 & 1338 & $13.07 \%$
\end{tabular}

\footnotetext{
* Numerator: Number of unused blood ordered in a month (bag)

**Denumerator: Number of all blood ordered within a similar month (bag)
} 
order before the implementation of the audit system was $24.1 \%$, and the average after the audit system application was $18.705 \%$. Therefore, the average decrease in the incidence of unused blood order before and after the audit system was 5.395\%.

The incidence of unused blood order, especially in the Department of Internal Medicine before and after the implementation of audit systems is shown in Table 2.

Just as the target of the Hospital, the target of unused blood order at the Department of Medicine was also $10 \%$. The average of unused blood order before the audit was $18.042 \%$, and after the application of the system and after the implementation of audit systems was $12.875 \%$. Thus, the average decrease amounted to $5.167 \%$.

Some causes of unused blood order in the Department of Internal Medicine is illustrated in Figure 1.

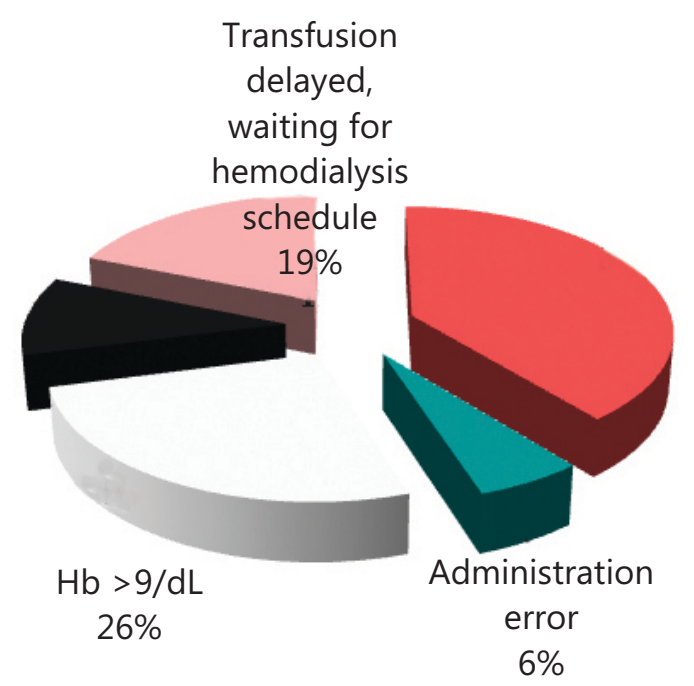

Figure 1. The causes of unused blood order PRC in internal medicine (the first month of audit)

The most common cause of unused blood orders was the patient's death (39\%), followed by the achievement of hemoglobin levels (26\%), transfusion on delayed due to patients fever $10 \%$ and waiting for hemodialysis schedule 19\%. Six percent is caused by administrative errors such as incorrect prescriptions (Figure 2).

The first cause of unused blood order on the PRC component was the achievement of hemoglobin levels (49\%), followed by transfusion on delayed due to patient waiting for hemodialysis schedule $29 \%$ and the patient died 22\% (Figure 3).

In the first month of the audit, the causes of

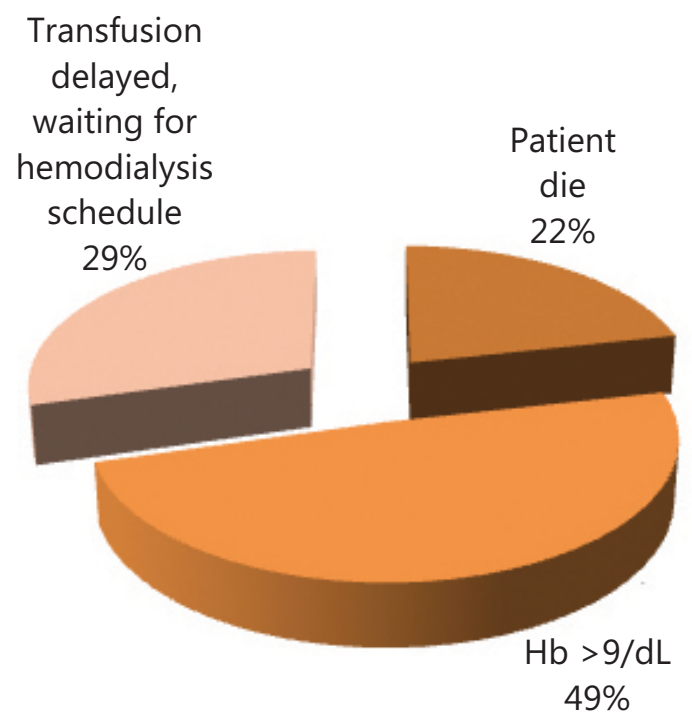

Figure 2. The causes of unused blood order PRC in internal medicine (the second month of audit)

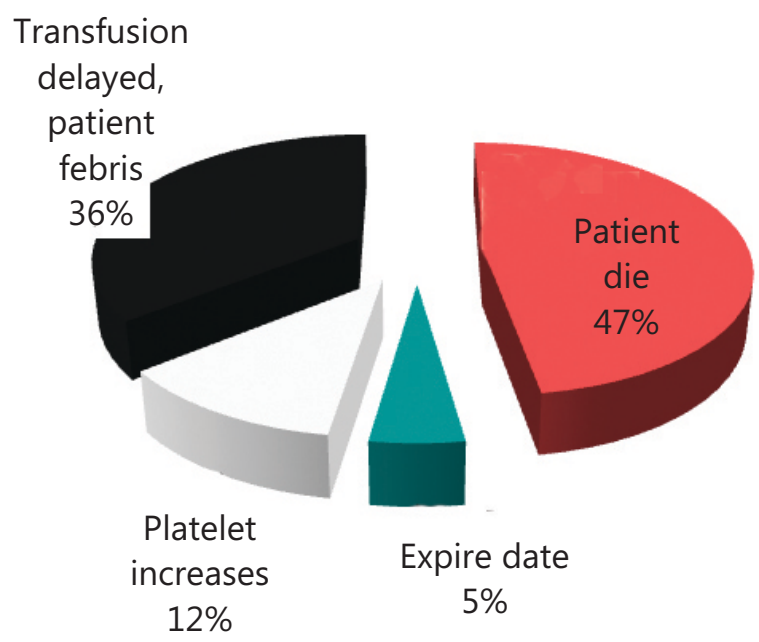

Figure 3. The causes of unused blood order TC in internal medicine (the first month of audit)

unused blood order in thrombocyte concentrate were patient died $47 \%$, followed by transfusion delayed due to patient fever $36 \%$, platelet increases $12 \%$ and expires date on product 5\% (Figure 4).

In the second month of the audit, unused blood order mostly cause by platelet increases by $72 \%$, followed by the expiry date of product $14 \%$ and $14 \%$ unknown causes.

The decline in $\mathrm{C} / \mathrm{T}$ Ratio before and after the implementation of audit systems in Sanglah Hospital 


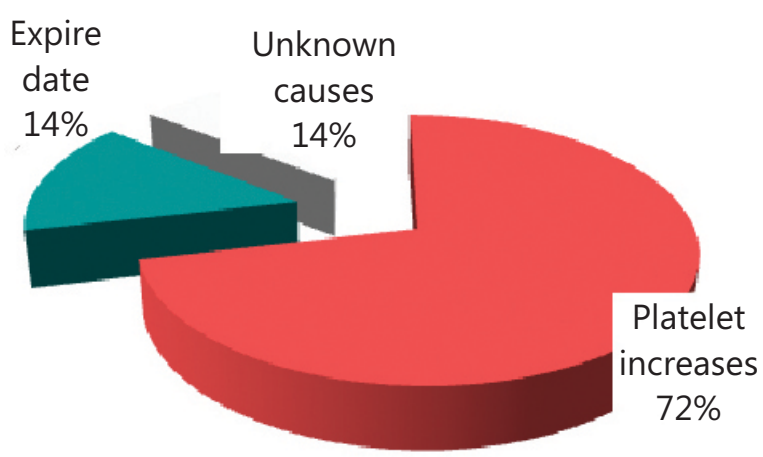

Figure 4. The causes of unused blood order TC in internal medicine (the second month of audit)

is shown in Table 3.

From Table 3, the mean of C/T Ratio before the application of the system is 1.324 and the mean after the audit system implementation is 1.23 . Thus, the mean decrease is 0.094 . Specifically, in the Department of Internal Medicine, the decline in $\mathrm{C} / \mathrm{T}$ Ratio before and after the implementation of audit systems is shown in Table 4.

From Table 4, the mean of $C / T$ Ratio before the implementation of the system was 1.22 , and the mean after the audit system implementation was
1.148. Thus, the mean decrease is 0.072 .

Reduction in the incidence of Unused Blood Order that occurred after the implementation of audit systems at the Sanglah Hospital and especially in the Internal Medicine Department was $5.4 \%$ and $5.2 \%$. Despite the decline achieved was not too big, but it helps in regulating blood supply and in preventing the costs for pre-transfusion examination. More than 80 units of blood could be used to help regulate blood stocks and reduce the waste of some costs for pre-transfusion testing.

The incidence of unused blood order which caused by the patient's death is difficult to prevent. However, communication between the room attendant and the Blood Bank must be maintained. The room attendant should immediately inform the blood bank that patients who needed blood has died, and the blood that has been ordered not to be used. Thus the blood can be immediately circulated to other patients. This research greatly helps to regulate blood stocks and maintain the quality of the blood, because the storage time becomes shorter.

In the transfusions of PRC and TC, the incidence of overestimation of the high demand for blood. What is meant by overestimation is the excess demand on

Table 3. C/T Ratio before and after the blood audit system was applied in Sanglah General Hospital Month

\begin{tabular}{lccc}
\hline Month & $\begin{array}{c}\text { The number of unit } \\
\text { crossmatched }\end{array}$ & $\begin{array}{c}\text { The number of units } \\
\text { transfused }\end{array}$ & $\begin{array}{c}\text { C/T Ratio } \\
\text { Sanglah Hospital }\end{array}$ \\
\hline January & 2613 & 1999 & 1.307 \\
February & 2023 & 1437 & 1.408 \\
March & 2590 & 1936 & 1.338 \\
April & 2553 & 1960 & 1.303 \\
Mei & 3093 & 2462 & 1.256 \\
Juni & 2773 & 2240 & 1.238 \\
July & 2856 & 2318 & 1.232 \\
The first month of audit & 2701 & 2201 & 1.227 \\
The second month of audit & 2502 & 2029 & 1.233 \\
\hline
\end{tabular}

Table 4. The C/T Ratio before and after blood audit system applied in the Internal Medicine Department

\begin{tabular}{lccc}
\hline Month & $\begin{array}{c}\text { The number of unit } \\
\text { crossmatched }\end{array}$ & $\begin{array}{c}\text { The number of } \\
\text { units transfused }\end{array}$ & $\begin{array}{c}\text { C/T Ratio } \\
\text { Sanglah Hospital }\end{array}$ \\
\hline January & 1824 & 1520 & 1.200 \\
February & 1777 & 1455 & 1.221 \\
March & 1706 & 1380 & 1.236 \\
April & 1263 & 1040 & 1.214 \\
Mei & 1318 & 1072 & 1.229 \\
Juni & 1769 & 1536 & 1.152 \\
July & 1597 & 1381 & 1.156 \\
The first month of audit & 1295 & 1131 & 1.145 \\
The second month of audit & 1338 & 1163 & 1.150 \\
\hline
\end{tabular}


the number of units of blood compared with the patients' needs. This case can be caused as a result of non-optimal dissemination guidelines for rational use of blood and the need for periodic re-education. Some cases of elevated levels of hemoglobin $>11 \mathrm{~g} / \mathrm{dL}$ are found. The increase of $\mathrm{Hb}$ levels by more than $11 \mathrm{~g} / \mathrm{dL}$ of post-transfusion is regarded as over-transfusion incidence. ${ }^{\text {? }}$

The persistently high incidence of unused blood order was caused by a delay of transfusion in patients who were awaiting hemodialysis, might be caused by a lack of communication between medical officers, the incompleteness of the information on blood requests and constraints in the hemodialysis service system.

The delays of transfusion for patients experiencing febrile were sufficiently contributing to the incidence of unused blood order. No literature says if a transfusion can be given while the patient is on fever or it has to wait for the normal body temperature. In some sources mention that before, during, and after the transfusion is done, the temperature monitoring should be carried out. If the temperature changes significantly during the monitoring, it should be considered that a transfusion reaction can cause the increase in temperature. If there are medications that need to be given prior to a blood transfusion, it must be given before the transfusion is done. If the medicine is given orally, the transfusion should be done 30-60 minutes after administration. If the medication is given intravenously, transfusion shall be conducted 10 minutes after the drug administration. ${ }^{8}$

Administrative errors that were found in this study was due to two things. Firstly because the same patients had two different names, and the information on the blood's request forms was not the same as those included in the billing system of the hospital. The second cause was due to an error on the writing of the request type of blood component. It was supposedly the Wash Red Cells (WRC) but at the written request was the PRC. Although the administrative errors that found in this study were not fatal, the completeness and accuracy of the writing of blood requests remained to be fixed.

The unused blood order incident happened because the platelets underwent expired products likely to be caused by a lack of communication between the room attendant and the officers of the Blood Bank. Another possibility that the implementation of the rules was not monitored, e.g., TC, which was not used within $2 \times 24$ hours after the pretransfusion tests could be circulated to other patients. This is because the storage life of TC is so short that it lasts only for five days.

The researcher had not found any similar studies that evaluated the effect of an audit system on the decline of unused blood order, but other studies that evaluated the effect of an audit system on the decrease in inappropriate transfusion had been done. Tuckfield et al. Conducted the study that results showed the auditing system of blood product usage was capable of lowering the inappropriate transfusion in the PRC component of $81 \%$, $52 \%$ of FFP and TC of $81 \%{ }^{9}$

Other research conducted by Giovanetti et al. who found a decline in the inappropriate transfusion in the PRC component of approximately $67 \%$ after application of the audit system and the use of blood product usage guidelines as instruments of research. '. Sarode et al. conducted a prospective audit by providing education to clinicians on the use of components of Pack Red Cells (PRC), Fresh Frozen Plasma (FFP), Thrombocyte Concentrate (TC). Results of the study significantly lowered the amount of $60 \%$ of plasma transfusions and platelet transfusions by $25 \%$ and cost savings, amounting to $\$ 3$ million over four years. ${ }^{10}$

From the results of this study, it was found a decline in the $C / T$ ratio, both in Sanglah General Hospital and particularly in the Department of Internal Medicine. The decline in the $\mathrm{C} / \mathrm{T}$ Ratio before and after the implementation of audit systems was respectively of 0.094 and 0.072 . Based on the research conducted at the Royal Glamorgan Hospital, South Wales, the $C / T$ ratio was high, in addition to causing an increasing amount of expiry blood, it also led to an increase in the workload of the blood bank personnel. ${ }^{11}$

A crossmatch transfusion ratio, or can be abbreviated as CTR 2.5: 1 is generally accepted as the highest limit related to the efficiency of the use of blood products. ${ }^{7,12,13}$ Maximum crossmatch to transfusion ratio 2:1 is recommended by another guidelines. ${ }^{14}$ In addition to improving patient safety due to a reduced risk of transfusion, lower $\mathrm{C} / \mathrm{T}$ ratio also saves the cost, time and energy. ${ }^{10}$ At the Army Hospital, Delhi, C/T Ratio that deemed to be acceptable is 2: 1 and C/T Ratio $1: 1$ is considered the most ideal and most efficient although it is never reached. ${ }^{15,16}$

\section{CONCLUSION AND SUGGESTION}

During the application of audit system for blood products usage, a decline in the incidence of unused 
blood order was at $5.4 \%$ in the Sanglah General Hospital and $5.2 \%$ in the Department of Internal Medicine of Sanglah General Hospital. The causes of the occurrence of unused blood orde at the Department of Internal Medicine. Were the patient died, overestimation of the request for blood, the delay of transfusion because of the waiting time for the schedule of hemodialysis, transfusion was delayed because patients experienced febrile, expired products, and the administrative errors.

For the indicator of C/T Ratio, either in general at the Sanglah General Hospital, and specifically in the Department of Internal Medicine had been a decrease at the time before and after the application of the audit system. The decline were respectively 0.094 and 0.072 .

\section{REFERENCES}

1. Sanglah Hospital Blood Bank: The annual report the use of blood products. Sanglah Hospital, 2012; 31-40.

2. Etchells $M$, Spradbrow J, Cohen R, Lin Y, Armali C, Lieberman L, et al. Audit of appropriate use of platelet transfusions: Validation of adjudication criteria. The International Journal of Transfusion Medicine. Vox Sanguinis, 2018; 113: 40-50.

3. Voak D, Napier JAF, Boulton FE, Cann R, Finney RD, Fraser ID, et al. Guidelines for implementation of a maximum surgical blood order schedule. Clinical Laboratory Haematology, 1990; 12: 321-327.

4. Mittal M, Agrawal J, Singh A. Transfusion audit of blood components in a tertiary care hospital. International Journal of Medicine Research, 2016; 1(3): 01-03.

5. Wittauer GJ, Jungbauer C, Turek P, Masopust J, Walterova L, Kullaste R, et al. Manual of Optimal Blood Use. Europe, 2010; 4-60.

6. McClelland. Handbook of transfusion medicine. United Kingdom Blood Services. $4^{\text {th }}$ Ed., United
Kingdom, The Stationery Office, 2007; 6-45

7. Lim EJ, Lopez CG, Veera SN, Menakan N, Aminah A. Efficiency of blood usage for elective surgery in the University Hospital Kuala Lumpur. Malaysian J Pathol, 1996; 18(2): 107-112.

8. Nester T, Aubuchon JP. Hemotherapy decisions and their outcomes. Technical manual $17^{\text {th }} A A B B$. American Association of Blood Bank. The United State 2011; 571-604.

9. Tinmouth A, Stanworth S. Approaches to blood utilization auditing. Technical manual $17^{\text {th }}$ Ed. AABB. The United States, 2011; 763-773.

10. Sarode R, Refaai MA, Matevosyan K. Prospective monitoring of plasma and platelet transfusions in a large teaching hospital results in significant cost reduction. Transfusion, 2010; 487-92.

11. Mehra A, Murray J, de Alwis C. A safe, simple and costeffective protocol for blood transfusion in primary total knee replacement. Ann R Coll Surg Engl, 2004; 86: 260-262.

12. Jayaranee $S$, Prathiba $R$, Vasanthi $N$, Lopez CD. A analysis of blood utilization for elective surgery in a tertiary medical centre in Malaysia. Malaysian J Pathology, 2002; 24(1): 59-66.

13. Soomro R, Ali SA, Javed MR. Blood transfusion arrangements and use of blood in elective surgical procedures. Professional Med J, 2011; 18(2): 212-214.

14. Alghamdi S, Gonzalez B, Howard L, Zeichner S, La Pietra A, Rosen $G$, et al. Reducing blood utilization by implementation of a type and-screen transfusion policy a single-institution experience. Am J Clin Pathol, 2014; 141: 892-895.

15. Gupta PK, Kumar H, Diwan RN. Blood order strategies in the armed forces. MJAFI, 2003; 59: 302-305.

16. Spradbrow J, Cohen R, Lin Y, Armali C, Collins A, CseriGazdewich, et al. Evaluating appropriate red blood cell transfusions: a quality audit at 10 Ontario Hospitals to determine the optimal measure for assessing appropriateness. Transfusion AABB, 2016; 56: 2466-2476. 